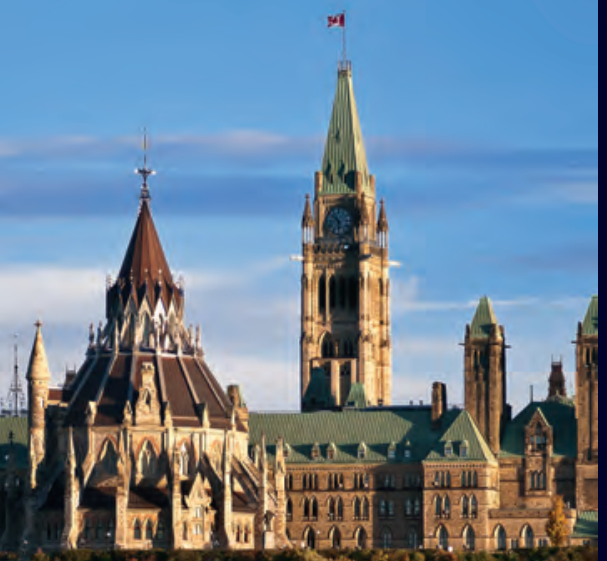

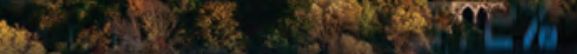

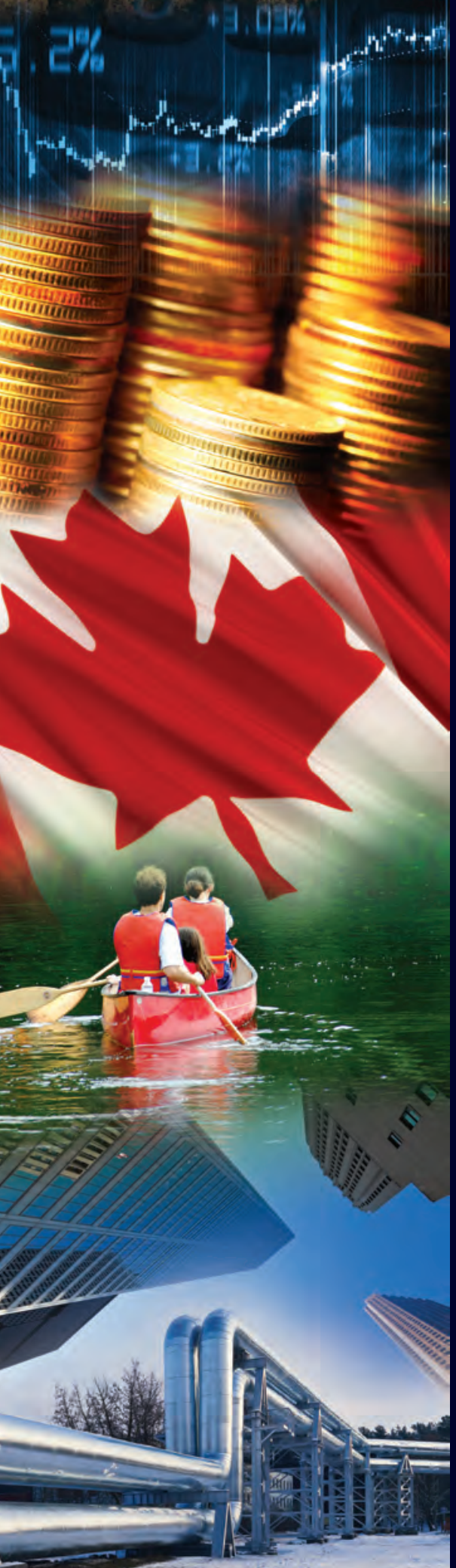

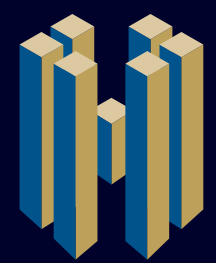

\section{institut C.D. HOWE institute}

COMMENTARY

NO. 540

\title{
Central Banks and the Future of Money
}

Policymaking circles are debating the pros and cons of making central bank digital currencies (CBDCs) available to the general public. While they debate the issues at stake, central bankers need to understand that maintaining the status quo is unlikely to be a practicable option.

\author{
John D. Murray
}




\section{THE C.D. HOWE INSTITUTE'S COMMITMENT TO QUALITY, INDEPENDENCE AND NONPARTISANSHIP}

\section{ABOUT THE AUTHOR}

John D. Mur ray served as Deputy Governor of the Bank of Canada from January 2008 until his retirement from the Bank in April 2014. As a member of the Bank's Governing Council, he shared responsibility for decisions with respect to monetary policy and financial system stability, and for setting the strategic direction of the Bank.
Commentary No. 540

April 2019

Financial Services and

Regulation;

Monetary Policy
$\$ 12.00$

ISBN 978-1-989483-02-2

ISSN 0824-8001 (print);

ISSN 1703-0765 (online)
The C.D. Howe Institute's reputation for quality, integrity and nonpartisanship is its chief asset.

Its books, Commentaries and E-Briefs undergo a rigorous two-stage review by internal staff, and by outside academics and independent experts. The Institute publishes only studies that meet its standards for analytical soundness, factual accuracy and policy relevance. It subjects its review and publication process to an annual audit by external experts.

As a registered Canadian charity, the C.D. Howe Institute accepts donations to further its mission from individuals, private and public organizations, and charitable foundations. It accepts no donation that stipulates a predetermined result or otherwise inhibits the independence of its staff and authors. The Institute requires that its authors disclose any actual or potential conflicts of interest of which they are aware. Institute staff members are subject to a strict conflict of interest policy.

C.D. Howe Institute staff and authors provide policy research and commentary on a non-exclusive basis. No Institute publication or statement will endorse any political party, elected official or candidate for elected office. The views expressed are those of the author(s). The Institute does not take corporate positions on policy matters.
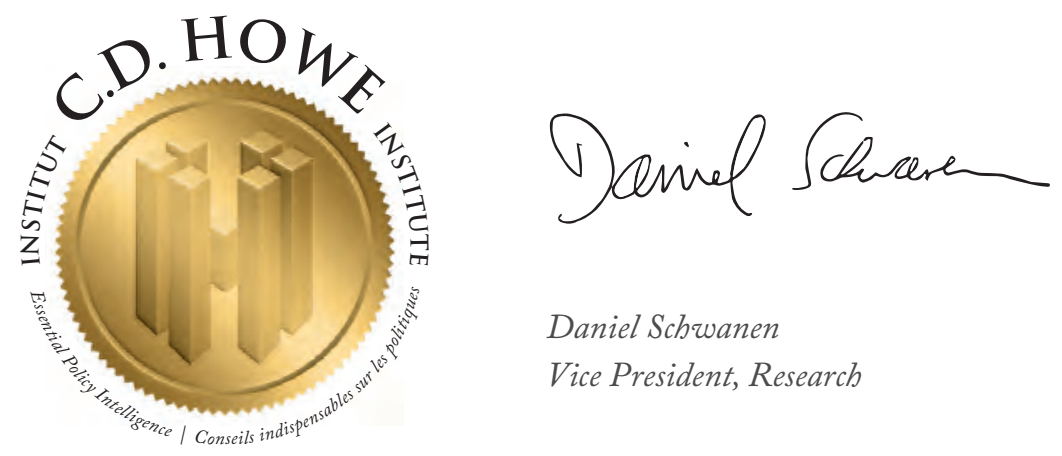

Daniel Schwanen

Vice President, Research 


\section{THE STUDY IN BRIEF}

Policymaking circles and central banks around the world are now giving serious consideration to the pros and cons of making central bank digital currencies (CBDCs) available to the general public. While the consensus view remains that such a move would be premature, opinion appears to be shifting. Indeed, developments in a number of advanced and emerging economies indicate that the CBDC model is receiving more serious consideration than it has in the past. The numerous speeches and research papers coming from central banks are testament to this growing interest. Moreover, some countries and central banks have moved beyond talking and have taken active steps to push the initiative further.

Proponents view the introduction of $\mathrm{CBDCs}$ as a potentially positive development rather than a purely defensive reaction. Indeed, they believe CBDCs could materially improve the role of central bank money in the financial system by providing a more stable unit of account, a more efficient medium of exchange and a more secure store of value. Moreover, the potential benefits go well beyond these traditional central bank money functions. Proponents suggest that CBDCs could temper financial instability, improve the implementation and transmission of monetary policy, raise productivity, help finance government deficits, reduce tax evasion and discourage a number of other costly and illegal activities.

These positive claims have not gone unchallenged. The most common concern raised is the destabilizing effect that CBDCs might have on the economy in times of financial stress. As a safe and convenient alternative to commercial bank deposits and other types of private financial assets, CBDCs might act as a dangerous accelerant in the context of a bank run, transforming an isolated concern about one bank's solvency into a system-wide crisis. Another source of concern is the disruptive effect that CBDCs would likely have on the competitive position of commercial banks, other financial institutions and key financial market infrastructures.

In the end, the best way forward for Canada and other countries may not involve the introduction of a CBDC. Some active government engagement now would nevertheless seem advisable to ensure the most promising ways forward are not precluded. Simply leaving it to the market to sort out would be very risky. The disruption caused by any policy reversals that might be contemplated at a later stage could prove insurmountable, leaving us in a place we would rather not be. It is important to understand that maintaining the status quo is unlikely to be a practicable option, given the shifting financial landscape. The question is not whether central banks will need to react, but how they should react to these tectonic technological shocks.

C.D. Howe Institute Commentary ( $)$ is a periodic analysis of, and commentary on, current public policy issues. Michael Benedict and James Fleming edited the manuscript; Yang Zhao prepared it for publication. As with all Institute publications, the views expressed here are those of the author and do not necessarily reflect the opinions of the Institute's members or Board of Directors. Quotation with appropriate credit is permissible.

To order this publication please contact: the C.D. Howe Institute, 67 Yonge St., Suite 300, Toronto, Ontario M5E 1J8. The full text of this publication is also available on the Institute's website at www.cdhowe.org. 


\section{Recent technological advances and growing competitive pressures have turned central bank digital currencies $(\mathrm{CBDC})$, once viewed as a fanciful, out-of-the-box idea into a practical possibility.}

Policymaking circles are now giving serious consideration to the pros and cons of making CBDCs available to the general public. While the consensus view remains that such a move would be premature, ${ }^{1}$ opinion appears to be shifting. Indeed, steps have been taken in one or two countries with a view to making $\mathrm{CBDC}$ a reality.

The main driver for this change is technology, which has made the improbable eminently possible. The reaction of central banks to the challenges this might pose has been understandably cautious and somewhat defensive up to this point, concerned largely with what it might imply for financial stability and the ability of central banks to fulfill their core responsibilities. Supplying digital currencies in the form of circulating tokens or accounts held directly at the central bank is seen by many as something that might eventually be necessary, owing to the encroachments of Fintech innovations such as Bitcoin and other private-sector variants, but nothing that is viewed with great enthusiasm.

Another group has come to the fore more recently, however, and sees $\mathrm{CBDC}$ s more favourably. It views the introduction of CBDCs as a potentially positive development rather than a purely defensive reaction. Indeed, it believes CBDCs could materially improve the role of central bank money in the financial system by providing a more stable unit of account, a more efficient medium of exchange and a more secure store of value. Moreover, the potential benefits go well beyond these traditional central bank money functions. Proponents suggest that CBDCs could temper financial instability, improve the implementation and transmission of monetary policy, raise productivity, help finance government deficits, reduce tax evasion and discourage a number of other costly and illegal activities.

These positive claims have not gone unchallenged. The most common concern that has been raised is the destabilizing effect that CBDCs might have on the economy in times of financial stress. As a safe and convenient alternative to commercial bank deposits and other types of private financial assets, CBDCs might act as a dangerous accelerant in the context of a bank run, transforming an isolated concern about one bank's solvency into a system-wide crisis. Other CBDC critics point to the loss of anonymity that such a currency might involve and the risk of vesting too much power and responsibility in the hands of government (Big Brother). The disruptive effect that CBDCs would likely have on the competitive position of commercial banks, other financial institutions and key financial market infrastructures is also a source of concern.

This Commentary examines each of these claims and counterclaims. I start by outlining the various forms that a CBDC might take and their

The author thanks Jeremy Kronick, Steve Ambler, John Crow, Paul Jenkins, David Laidler, Thorsten Koeppl, Angelo Melino, Gregor Smith, Chris Taylor, anonymous reviewers and members of the Financial Research Initiative of the C.D. Howe Institute for comments on an earlier draft. He retains responsibility for the views expressed.

1 See, for example, Bank for International Settlements (2018). 
distinguishing features relative to other means of payment. Within this discussion, I provide a brief description of the account-based CBDC model that appears to offer the most promise in terms of maximizing potential benefits to the real economy. I then review the prospective advantages of such a CBDC from three different perspectives: its impact on the payment system, monetary policy and financial stability. The Commentary ends with a detailed review of the various caveats and counterarguments that have been put forward against such a proposal.

My primary purpose is not to advocate on behalf of any one CBDC or for CBDCs in general. Rather, it is to give interested readers a high-level appreciation of the major issues at play and the pros and cons of alternative policy paths. That said, it is important to understand that maintaining the status quo is unlikely to be a practicable option, given the shifting financial landscape. The question is not whether central banks will need to react, but how they should react to these tectonic technological shocks.

\section{WHAT DO WE MEAN BY CENTRAL BANK DIGITAL CURRENCY?}

There is nothing new about the idea of central bank money. The $\$ 88$ billion of banknotes currently on the Bank of Canada's balance sheet and circulating throughout the Canadian economy provide tangible evidence of this. Neither is there anything new about the idea of virtual central bank money. ${ }^{2}$ Commercial banks have had digital accounts on most central banks' balance sheets since the early 1970s as part of the reserve settlement system. What is new is the idea that central bank digital money might be made available to the general public and entities other than commercial banks.
This CBDC could take the form of a deposit, similar to those that people hold at commercial banks, or a digital token, exchanged using distributed ledger technology and functioning in the economy much like banknotes do today.

Currencies can be distinguished according to four fundamental properties: ${ }^{3}$ issuer, form, accessibility and technology. Issuer refers to whether government or a private entity is providing the currency. Form refers to whether the currency is physical or virtual; i.e., digital. Accessibility refers to whether the currency can be widely held (general purpose) or by a restricted set of entities such as commercial banks, other financial institutions and corporations (wholesale accounts). Technology refers to the means by which currency is exchanged - peer-to-peer or via an intermediary.

Banknotes, for example, are issued by the central bank, have a physical form, are general purpose in nature and exchanged peer-to-peer (i.e., payer to payee). No intermediary or authorization is needed for their use, although users have to ensure that they are not counterfeit.

Digital tokens issued by a central bank would be like banknotes in many respects. They would be legal tender, liabilities of the central bank and designed for peer-to-peer transactions. Owing to the direct nature of the peer-to-peer exchange, central bank digital tokens, like banknotes, could be used anonymously, leading to concerns about their possible misuse for money laundering, terrorist financing, tax evasion and other "off-market" activities.

The main difference between the two types of currency is that one is physical and the other is virtual. As with banknotes, care would have to be taken to ensure the digital tokens were not counterfeit. But unlike banknotes, users would have

2 See Tobin (1987).

3 This discussion is based on the "money flower" analysis of Bech and Garratt (2017). 
to ensure that the digital tokens had not already been spent by another party. ${ }^{4}$ Considerable reliance would also have to be placed on the distributed ledger technology supporting the creation and transfer of these digital tokens.

Account-based CBDCs are different from banknotes and digital tokens in several respects. ${ }^{5}$ They would be held as deposits at the central bank and require its assistance to complete a transaction. In this regard, they would operate much like debit cards on a commercial bank account. However, unlike banknotes and digital tokens that require payees and payers to verify the legitimacy of the currency (i.e., whether it is counterfeit), accountbased digital currencies require an intermediary (central bank or commercial bank) to verify the ownership of the funds and arrange for their transfer. ${ }^{6}$ Importantly, whereas it is impossible to pay interest on physical banknotes, and very difficult - if not impossible - in the case of digital tokens, it is quite simple to do so for account-based currencies.

While either the token or the account-based version of $\mathrm{CBDC}$ s could function in the economy, and might serve as a convenient point of departure for the analysis that follows, most of our attention will be focused on the account-based CBDC for reasons that should become clear later in the Commentary.
The account-based CBDC used for purposes of our analysis has three distinguishing features:

(1) it is a general-purpose currency, as opposed to being restricted to a particular set of people or institutions;

(2) it is interest-bearing, best viewed as an alternative to retail deposits at commercial banks; and

(3) it is backed on the asset side of the central bank's balance sheet by liquid federal government securities. In other words, the central bank would not use the CBDC for any commercial or personal lending activities.

With this as background, we can now proceed to an analysis of the major advantages and disadvantages that might be associated with this CBDC.

\section{IMPLICATIONS FOR THE THREE BASIC MONEY FUNCTIONS ${ }^{7}$}

A natural starting point for any analysis of a new currency is to ask how well it could fulfill the three basic money functions; namely, serving as (1) a unit of account, (2) a medium of exchange and (3) a store of value.

It is perhaps easiest to begin at the end - with the store of value function. As noted above, an obvious advantage that the account-based CBDC would have over banknotes and digital tokens is the ability to pay interest, thereby overcoming a fundamental economic inefficiency related to cash,

4 Chapter V, “Cryptocurrencies: Looking Beyond the Hype," in the Bank for International Settlements's Annual Economic Report 2018 provides a detailed and readable explanation of the various practical problems that can plague cryptocurrencies and blockchain technologies.

5 Couched in terms of Bech and Garratt's four-part "money flower" analysis, account-based CBDCs would be issued by the government, in virtual form, transferred via an intermediary, and perhaps be widely accessible (depending on their intended purpose).

6 Verification is an important function, and this Commentary implicitly assumes that central banks would be capable of performing it. The role would presumably be made easier by the centralized nature of the operation and the transaction's straightforward nature. However, a partnership with the private sector for this and other deposit-servicing activities could be contemplated if it were found to offer a more efficient solution.

7 The next three sections draw heavily from the work of the Bank for International Settlements (2018) and Bordo and Levin (2017). 
as highlighted by Friedman (1960). ${ }^{8}$ Commercial banks also offer deposits that pay interest but, unlike account-based CBDCs, their deposits are less secure since they are subject to liquidity and credit risk. An account-based CBDC, in contrast, would be default free by definition and always accessible.

In addition, the economies of scale that might be realized through the centralization of deposits could allow the central bank to pay higher rates of interest on demand and savings deposits than commercial banks do. The absence of any need for deposit insurance in the case of account-based CBDCs would be a further advantage.

An even more significant competitive advantage that central bank deposits would enjoy concerns the absence of "cross-subsidization" and the much lower overhead costs that would need to be covered. If banknotes still circulated in the economy, a simple ATM would presumably suffice for accessing paper currency; otherwise no additional external physical infrastructure would be required for account-based CBDCs. All transactions would be conducted through direct electronic links between depositors and the central bank.

More importantly, a large share of the revenue currently generated by retail deposits at commercial banks is typically used to help underwrite or crosssubsidize the expenses that commercial banks incur elsewhere in their operations. Examples include offering higher interest rates than might otherwise be possible on wholesale deposits, offering lower lending rates to large corporate customers, paying higher dividends to shareholders and spreading the overhead costs of an extensive branch-banking network. ${ }^{9}$ Existing competitive pressures in the banking sector do not seem to be sufficient to eliminate these excess margins. The lower interest rate sensitivity and sticky nature of retail deposits allow commercial banks to engage in this sort of cross-subsidization without eroding their retail deposit base. Absent convenient alternatives, depositors are extremely reluctant to switch institutions or shift funds to other instruments.

The introduction of account-based CBDCs could be a significant game changer. Central banks could then provide an attractive alternative, offering interest rates on CBDC deposits that are only slightly lower than the returns generated by the government securities held on the asset side of the central banks' balance sheets. The lost seigniorage (profit from issuing currency) that paying interest would entail would have to be carefully considered, but in a world of declining banknote use, this may not represent a serious opportunity cost. ${ }^{10}$ Commercial banks could respond to these competitive pressures by eliminating crosssubsidization, thereby removing potentially important price distortions in the market, but might find it challenging to run their various business lines on a self-financing, standalone basis.

There is also reason to believe that accountbased CBDCs could serve as a cheaper, more secure and more efficient medium of exchange than

8 Friedman worried that cash, which is essentially costless to produce, would nevertheless be underutilized in the economy since, unlike other riskless government liabilities, it could not pay an explicit nominal rate of interest. His answer to this evident inefficiency was to have the central bank engineer a modest rate of deflation in the economy, thereby providing a positive real rate of interest on cash. Other economists have worried about the negative side effects that would likely accompany Friedman's optimal, deflationary, rate of inflation.

9 Some of the fees that banks charge are used to defray the various costs associated with servicing retail deposits, but appear to go well beyond what is required in this regard.

10 Banknote usage relative to GDP has not shown any signs of declining in Canada, unlike in many other countries. However, judged by various other measures, its importance has been shrinking and may face greater headwinds in the future. See Henry et al. (2018). 
any of the other alternatives. Operating costs should be lower, ${ }^{11}$ and payments and settlements should be virtually instantaneous, eliminating float. In addition, there would not be any risk of a run on the central bank or worries about the counterparty's creditworthiness. The counterfeiting problems associated with banknotes would also be eliminated. Token-based CBDCs might offer some of these advantages but are very costly to produce and transfer, based on existing distributed ledger technology. ${ }^{12}$ They are also subject to greater operational risks and, in the case of private digital currencies, to extraordinary swings in their market value. ${ }^{13}$

Account-based CBDCs also hold the promise of a more stable unit of account - one that is defined in constant real terms (i.e., protected from the corrosive effects of inflation) as opposed to constant nominal terms. Economists going back as far as William Stanley Jevons in the late $19^{\text {th }}$ century have recognized the advantages of a currency that was able to preserve its purchasing power through time. They also advanced a number of imaginative but, in the event, infeasible and unpromising schemes by which this might be achieved. These included proposals such as Jevon's Tabular Standard of Value and Irving Fisher's Compensated Dollar. Although the intent was admirable, each of these early schemes suffered from serious operational challenges and other unattractive features that rendered them impractical.

An account-based CBDC should be able to overcome these practical constraints, allowing the early economists' vision to finally be realized. ${ }^{14}$
This could be accomplished directly by regularly adjusting the currency's value through time to preserve its purchasing power or by a monetary policy aimed at delivering true nominal price stability (see below). Such a system would remove an important source of uncertainty and provide a more reliable base for the spending and investment decisions of households and businesses.

Most central banks in developed countries currently operate under an inflation-targeting regime designed to deliver a low and stable rate of inflation. In many cases, the target rate is 2 percent or slightly higher. Even when this objective is met, however, households and businesses still face significant risks and a serious loss of purchasing power through time. Agents in the alternative, account-based CBDC world would be able to go about their business with greater confidence in the future value of money.

To the extent a secure and remunerated currency hastened the demise of cash, broader and potentially more important benefits might also be realized. ${ }^{15}$ Money laundering, terrorist financing, tax evasion and other forms of criminal activity would all be rendered more challenging and easier for authorities to track. Even if cash were able to coexist with an account-based CBDC, its importance would likely decline. At a minimum, authorities would find it much easier to withdraw high denomination banknotes from circulation, making it harder to undertake these off-market activities. Life for the misbehaved would be made more difficult.

11 Onerous cash management, storage and handling costs would be avoided, and the centralization of digital deposits would likely lead to significant economies of scale.

12 See the Bank for International Settlements Annual Economic Report 2018 and the "Report of the Committee on Payments and Market Infrastructure" (2018).

13 The technology needed to create, record and transfer private token-based digital currencies requires extraordinary amounts of energy. It also has been subject to a number of recent hacks and other misadventures.

14 See Jevons (1875) and Fisher (1913), as well as Marshall (1887), Wicksell (1898) and Hayek (1978).

15 See Rogoff (2016). 


\section{IMPLICATIONS FOR MONETARY POLICY}

Proponents of an interest-bearing, account-based CBDC believe it would benefit the implementation and transmission of monetary policy. Generalpurpose, interest-bearing accounts would make it much easier for central banks to target negative interest rates in response to serious economic downturns, obviating or at least minimizing the need for unconventional monetary-policy responses. Monetary policy, in other words, would become fully symmetric. Interest rates could be adjusted downward without limit, just as they can now be adjusted up without limit. Meanwhile, the operational aspects of conducting monetary policy would remain essentially unchanged. Inflows and outflows of funds would be automatically accommodated and their effects on the reserve base quickly neutralized, just as movements in banknote holdings and bank reserves are at present. However, central banks' ability to stabilize prices and output could be significantly improved.

Currently, the main obstacle to pursuing a symmetric monetary policy is the ability of households and businesses to circumvent the effects of negative interest rates by shifting their bank deposits and other financial assets into cash. This option sets an effective lower bound on how low central banks can push interest rates since, by construction, cash offers a zero nominal rate of interest. Removing most or all cash from the system, either through explicit government action or the competitive forces created by positive interest-bearing CBDCs in normal times, would effectively close this channel. ${ }^{16}$
Eliminating the problems posed by the effective lower bound on interest rates would also allow central banks to target true price stability as opposed to a low but modest rate of inflation, such as 2 percent. The reason most central banks operating under an inflation-targeting regime currently set a target of at least 2 percent is to provide additional room to lower interest rates in the event of an economic downturn. Elimination of the effective lower bound would obviate the need for any extra buffer. A more ambitious monetary policy objective would be, therefore, both feasible and appropriate. Other schemes have been proposed to achieve the same results without the introduction of an account-based CBDC, but all of them involve considerable complexity and have more limited chances of success. ${ }^{17}$

A final monetary policy advantage that supporters advance in favour of an account-based $\mathrm{CBDC}$ is the more direct control it might provide for setting interest rates. An account-based CBDC would give central banks a more direct channel into the interest rates faced by households and businesses, and avoid any unwanted slippages that might occur under the present system where movements in the central bank's target overnight interest rate are filtered through capital markets and the commercial banking system. Account-based CBDCs might also provide a more reliable realtime window on economic activity with which to guide monetary policy.

\section{IMPLICATIONS FOR FINANCIAL STABILITY}

From the perspective of financial stability, accountbased CBDCs' most obvious advantage is the

16 In the event cash continued to circulate in parallel with account-based CBDCs, authorities could buttress the new regime by imposing a variable fee schedule for agents wanting to convert large sums from their bank accounts into cash. Agents might be tempted to shift their funds into gold or foreign currencies, but each of these alternatives carries additional costs and risks.

17 See Buiter (2009). 
absence of any incentive for "runs" on CBDC deposits. Since they represent direct claims on the central bank, which can create money as needed, there is no credit or liquidity risk. ${ }^{18}$ Proponents believe the financial-stability benefits go far beyond the risk-free nature of CBDCs, however. To the extent they result in the migration of chequable deposits to the central bank and the elimination or reduced importance of cash, account-based CBDCs would effectively separate the creation of money as a transactions medium from the commercial lending activities of banks. In this sense, it is a variant of the "narrow banking" or "full-reserve money" idea advanced by Henry Simons (Simons 1936) during the depths of the Great Depression and subsequently promoted by several other notable economists, such as fellow University of Chicago academic Milton Friedman.

Simons proposed to reduce the probability of future financial crises by forcing commercial banks to back all their liabilities with federal government securities and, by this means, remove their ability to generate credit by simply creating deposits. The so-called Chicago Plan would not only ensure the deposits were fully backed by riskless government securities but also give government, via the central bank, complete control over the growth of intermediated credit and a cheaper source of debt financing. The issuance and trading of bonds and stocks under the Chicago Plan would continue just as before but be subject to much tighter regulation (e.g., Glass-Steagall Act).

The modern version of the Chicago Plan is not as severe as the original but is motivated in part by a similar desire to improve financial stability. The account-based CBDC proposal presented above would focus primarily on the retail end of the deposit chain; namely the demand-and-notice deposits of households and small businesses. A decision would have to be made concerning whether banknotes could continue to circulate, but commercial banks would presumably remain free to compete for retail deposits. One might expect, however, that market pressures would cause commercial banks to concentrate increasingly on the attraction of term deposits as a means of funding the loans they extended to households and businesses. The critical difference from a financialstability perspective would be their more limited opportunity to engage in maturity and liquidity mismatching. If this proved insufficient to assure greater financial stability, tighter oversight and regulation could be employed. ${ }^{19,20}$

18 Inflation risk might still be present if the central bank acts irresponsibly but, as described above, account-based CBDCs offer the possibility of greater price stability.

19 Some CBDC proponents have focused on the opposite end of the spectrum and suggested that their introduction should concentrate on the wholesale market (see Bank for International Settlements (2018)). Non-financial corporations, shadow banks and other institutions would be able to set up an account at the central bank exactly like the reserve accounts now held by banks and other direct clearers. This would have quite different implications for banks and their competitive position in the lending area and for those financial-market infrastructure entities involved in the payment and settlement process. Proponents hold out the prospect of a cheaper and more secure real-time settlement system on the central banks' books and a reduced need for collateral. Economies of scale in these activities, some would argue, create a natural monopoly that the public sector should actively manage rather ceding it to the private sector. Giving the private sector licence to appropriate the profits associated with such a concentrated market is regarded as unwarranted. Although the wholesale proposal is intriguing and potentially important, it is not examined here in further detail.

20 Even if some sight deposits remained in the commercial banking system, the liquidity needs would nevertheless be significantly reduced, along with the risk of a sudden liquidity run. In the event problems did occur, they could be dealt with by using standard tools such as the lender-of-last-resort facility and deposit insurance. 


\section{Possible Costs ANd Pitfalls}

Needless to say, the numerous benefits that CBDC supporters put forward have not gone unchallenged. The main concerns regarding the costs and feasibility of such a system are examined here along with some of the defenders' counterarguments.

\section{Loss of Privacy}

According to critics, one of account-based CBDCs' key negatives is the loss of anonymity that would result if they led to the demise of cash and no similarly anonymous means of payment, such as token CBDCs, were available. Critics worry that this would represent an unwarranted and potentially dangerous threat to privacy. It could give the government access to vast amounts of personal data and increase the likelihood of slipping into a Big Brother world. ${ }^{21}$ The risk of political interference might also be much greater.

Such arguments ignore the fact that a great deal of this information is already available to governments and to the private sector. Moreover, the difference between the government having access to it and having it held in a very concentrated private banking or social network system may not be very material. Is the private sector a more reliable guardian of privacy than the government? Admittedly, cash transactions preserve anonymity and keep information away from both the government and the private sector. However, this is also a source of growing concern. Large amounts of high-denomination banknotes are currently in circulation, yet are seldom seen in the normal course of business, raising suspicions that they are used principally for illegal, off-market activities. ${ }^{22}$ Efforts to preserve the role of cash in the payment system or to introduce a token-based rather than an accountbased CBDC system would have to weigh these costs against any prospective benefits in the form of privacy protection. The declining share of cash in most payments systems across developed economies indicates this base is eroding in any case. ${ }^{23}$

\section{Increased Risk of Bank Runs}

A second serious concern is the increased risk of bank runs in times of stress. CBDCs provide a convenient and risk-free alternative to commercial bank deposits that might encourage clients to run for the safety of CBDCs at the first sign of trouble. The result could be a system that is more secure in normal times but more prone to systemic failure in uncertain times. By providing an improved safe haven compared with cash, ${ }^{24} \mathrm{CBDC}$ might make the financial system more fragile, dragging down both suspect and stable institutions as depositors race for the exits.

Although this concern is not easily dismissed, one might expect account-based CBDCs would minimize the risk of a system-wide run, provided they eliminated or seriously reduced the commercial banking system's share of chequable and immediately cashable deposits. In theory, commercial banks' remaining liabilities would be more closely matched with bank assets in terms of their maturity and liquidity risk. The most worrisome ingredients for feeding a run, therefore, would be absent.

A system of fees and limits on the exchange of bank deposits for CBDC deposits could also be

21 The recent controversy concerning Statistics Canada's request for commercial bank data might suggest we are already there.

22 See Curry (2019).

23 See Bank for International Settlements (2018). Sweden is the most notable country in this regard. Circulating banknotes in Canada have remained equivalent to approximately 10 percent of GDP, but are declining in importance relative to other means of payment.

24 Account-based CBDCs would provide a positive rate of return (in most periods) and avoid the practical difficulties associated with accessing and safely storing large amounts of cash. 
used, as required, to control fund outflows. Many supporters of the account-based CBDC system also maintain that CBDCs would make it easier for central banks to provide immediate emergency relief and function more effectively as a lender of last resort.

Critics acknowledge these counterarguments and potential safeguards, but are nevertheless persuaded that, on balance, the financial system would become more fragile, making the increased risk of bank runs their most serious concern.

\section{Disruption of Commercial Banks' Business Model}

A third important worry is the damage that an account-based CBDC might do to the business model of commercial banks. Removing a key source of generally stable and cheap financing from the banks could severely impair bank profitability and perhaps encourage banks to pursue even riskier investments in a search for yield. Banks' ability to perform their most important function - efficiently and economically intermediating the flow of funds between savers and borrowers - might also be impaired. The returns banks could offer on term and wholesale deposits might decline, while the interest rates charged to borrowers would likely increase. Commercial banks' presence in the financial system would probably diminish with possible knock-on effects for growth and development.

In addition, economic performance might be negatively affected by the more limited contact banks would have with their customers and the added difficulty they might encounter in assessing credit worthiness and providing investment advice ("know your customer"). The end result could be a disrupted and much smaller banking sector, along with greater risk and lower productivity growth in the real economy.

That said, one might question whether it is the government's responsibility to preserve the banks' current business model if a better one exists. The benefits to businesses and the broader community have to be carefully weighed. Removing the distortions created via the cross-subsidization of the banks' business lines might improve the pricing of risk in the market as well as the allocation of funds across the economy. The overall impact on the cost of capital facing investors is unclear. Interestrate relationships through much of the financial system could be changed, but the end result, though uncertain, might be better. ${ }^{25}$

CBDC defenders also question how significant the loss of client interface would be. Banks would still have access to multiple sources of credit information, and much of today's lending is done through standard computer algorithms.

\section{Cyber Risk}

A fourth concern that is often flagged is the increased concentration of deposits that would likely accompany the introduction of account-based CBDCs and the implications for cyber risk. By putting many or most retail deposits in a common database at the central bank, the risk of a calamitous cyberattack or crippling hack could be greatly increased. CBDC critics note that diversifying your risk by spreading your eggs across a number

25 The possible disruption of the banks' business model is obviously an important consideration. It is difficult to know without further research and, perhaps, real-world experimentation how serious this threat might be with possible knock-on effects for the overall economy. For what it is worth, preliminary work at the Bank of England suggests there could be a significant net gain to the economy and the disruption would not be too severe (see Barrdear and Kumhof (2016)). Authorities would presumably make every effort to ensure a gradual transition to help ease the adjustment process. 
of baskets is surely a better way of guarding against a system-wide collapse and would also help to preserve competition in the financial system.

While cyber threats are a clear and present danger in today's economy, one can also argue that concentrating retail deposits in one place, with substantial backup, might provide greater security than the present system. More money and attention could be devoted to the maintenance and protection of deposit data than would be possible for any one bank, exploiting economies of scale and ensuring more frequent updates. Finally, the highly concentrated nature of Canada's commercial banking sector might cause one to question whether the diversification benefits provided by the current system are very meaningful. The enlarged balance sheet of the central bank would likely remain much smaller than the balance sheets of each of the big five banks and, viewed in this way, might actually provide an extra degree of diversification.

\section{Potential Operational and Practical Constraints}

The final set of concerns noted here involves a number of potentially important operational and practical constraints that could make the introduction of an account-based CBDC either impossible or ill-advised.

The first of these practical considerations relates to the difficulty and cost that would be associated with creating, operating and managing such a sizable system. Millions of accounts would have to be established and safeguarded, and billions of transactions would have to be executed each day. The additional responsibility placed on central banks would be significant and well beyond their normal course of business. Critics maintain that central banks would not have any comparative or absolute advantage relative to commercial banks in operating such a system. They note that the last time the Bank of Canada undertook a similar activity involved the sale and management of Canada Savings Bonds, which proved to be a very costly and labour-intensive operation, and was ultimately allowed to fade away.

That might not represent a reliable test case, however. Technological advances, modern computerized systems and the simpler, sole-purpose nature of an account-based CBDC system should help to address many of the problems that were encountered earlier with Canada Savings Bonds. Be that as it may, cost considerations and past experience would obviously have to be carefully reviewed before proceeding.

A further practical concern is the availability of sufficient federal government securities to backstop such a large and growing stock of CBDC liabilities. The outstanding stock of federal government debt in Canada currently is slightly more than $\$ 1$ trillion, while personal chequable and non-chequable notice deposits at banks total roughly $\$ 290$ billion and $\$ 250$ billion, respectively. Non-personal chequable deposits would add another $\$ 550$ billion. If all of these shifted onto the central bank's balance sheet, it would fully exhaust the available supply of government debt and leave nothing for the rest of the financial system where it serves as a vital source of liquidity and collateral, as well as a critical benchmark for the pricing of other securities.

One way of avoiding this would be to have the central bank hold other types of debt: sub-national government and private. However, one of the critical objectives in establishing a CBDC program is to avoid any intermediation or risk-taking on the part of the central bank. Another alternative would be to over-issue federal government debt, something that Australia has already done and the US actively considered in the late 1990s and early 2000s, when it looked like growing budget surpluses 
might seriously reduce the outstanding stock of US government debt. ${ }^{26}$

All of this assumes, of course, that every individual and business would elect to shift their chequable and notice deposits into a CBDC account. However, if only individuals and small businesses were allowed to have CBDC accounts, the potential demand would shrink noticeably. And if, as seems reasonable, many retail depositors decided to leave all or part of their money at commercial banks - perhaps for the convenience associated with one-stop shopping - the feasible set would grow even smaller. No one would be forced to hold a CBDC account under the proposed system, and commercial banks would still be free to compete for customer business. Indeed, this competition would represent an important part of the new system.

An additional step that could be taken, if necessary, in the early days of the CBDC program would be to impose further restrictions on access to the central bank accounts. This could be a useful means of easing the transition from the standpoint of the central bank and commercial banks, as well the financial system more generally. ${ }^{27}$

\section{CONCLUDING THOUGHTS}

Globalization and technological advances are going to produce radical changes in the financial system. The only question is what form these will take. There are tremendous first-mover advantages in a world characterized by significant network externalities and economies of scale. The sizable fixed costs required for many of the solutions that have been contemplated will make it difficult, if not impossible, to unwind anything that is initially put in place, even if subsequent analysis shows that a different model would have produced much better results. Serious consideration must be given to whether user or business interests should be given priority as we move forward.

Several important potential benefits and costs have been identified with regard to an accountbased CBDC model. Considerable risk and uncertainty also characterize much of what I have discussed. However, sustaining the status quo is unlikely to be an option.

Developments in a number of advanced and emerging economies indicate that the CBDC model is receiving more serious consideration than

26 The funds that the Canadian government received by issuing additional debt, if this option were pursued, could be invested in high-grade, foreign-national and supra-national debt. The interest earned on such investments would offset the extra servicing cost associated with the new debt. While such a scheme would be subject to foreign-exchange risk, this could be minimized by diversifying across major currencies. The plan would simply extend what the government already does to finance its foreign-exchange reserves.

27 It is worth noting that one or two of the practical concerns that critics of CBDCs frequently put forward have not been discussed in this section. They are technical in nature and can be better addressed in a detailed manner elsewhere. One relates to the willingness and ability of central banks to perform the sort of verification functions that are needed to process deposit transactions. Another relates to the legality of central banks entering this area and whether they could satisfy the "know your client" (KYC) requirements. A few quick observations on these issues are offered below, leaving it to others to explore them at greater length.

First, while KYC and verification are important, one suspects they could be more easily managed in a mono-line operation such as the one envisaged here. Central banks might actually have an advantage in fulfilling these tasks. No lending activities or credit extension would be involved with an account-based CBDC, and transactions could be tracked more easily. Any legal roadblocks that might exist could surely be dealt with if and when the initiative were found to be worth pursuing. Although this Commentary implicitly assumes that central banks would carry out verification and any other deposit-servicing functions that might be required, nothing would prevent them from establishing partnerships with commercial banks if they were viewed as a more cost-effective path. 
it has in the past. The numerous speeches and research papers coming from central banks are testament to this growing interest. ${ }^{28}$ Moreover, some countries and central banks have moved beyond talking and have taken active steps to push the initiative further.

Switzerland recently held a referendum to see if the public wanted to move to a system much like the "narrow banking" and CBDC model described here. It would have involved giving the Swiss National Bank the exclusive right to create money. The initiative was popularly referred to as Vollgeld - or Full Money. ${ }^{29}$ Although the proposal was defeated, it offers additional evidence that adoption of a CBDC system might be closer than one thinks.

Active efforts are also underway in the US private banking sector with a view to introducing something similar to the CBDC model. Last year, former senior officials of the Federal Reserve System received approval from the State of Connecticut to create a new bank. Its sole purpose would be to collect retail deposits and invest the funds as reserves at the Fed. Depositors would receive an interest rate marginally lower than the Fed-funds rate but substantially higher than what most demand-and-savings deposits currently promise. ${ }^{30}$ This is a private-sector initiative that would essentially duplicate what an account-based CBDC might offer, posing a similar competitive challenge to the commercial banking sector without offering some of the advantages that an accountbased CBDC might provide. State officials have determined that there is nothing illegal about the proposal. However, the Federal Reserve has delayed final approval without offering any reason why.

Finally, it is worth noting that there is one central bank that has already introduced a CBDC. The Central Bank of Ecuador launched its CBDC in 2014, but decided to withdraw it in early 2018 owing to a lack of public interest. While this might be viewed as a cautionary warning for similar initiatives that might be contemplated elsewhere, the circumstances were somewhat exceptional, at least from a developed country perspective. First, the Ecuadorian economy was already heavily dollarized. Second, as in many emerging economies, there was a deep distrust of the central bank. ${ }^{31}$

In the end, the best way forward for Canada and other countries may not involve the introduction of a CBDC. Potentially important costs have been identified along with potentially important benefits. Some active government engagement now would nevertheless seem advisable to ensure the most promising ways forward are not precluded. Simply leaving it to the market to sort out would be very risky. The disruption caused by any policy reversals that might be contemplated at a later stage could prove insurmountable, leaving us in a place we would rather not be.

28 See, for example, Andolfatto (2015), Broadbent (2016) at the Bank of England, Fung and Halaburda (2016) and Lane (2018) at the Bank of Canada, Mersch (2017) at the European Central Bank, Nicolaisin (2017) at the Norges Bank and Skingsley (2016) at the Riksbank.

29 See Atkins (2018).

30 See McAndrews (2017).

31 Interested readers who wish to learn more about this experiment are referred to the Central Bank of Ecuador's website at https://www.bce.fin.ec/en/index.php/electronic-money-system and White (2018). 


\section{REFERENCES}

Andolfatto, David. 2015. "Fedcoin: On the Desirability of a Government Cryptocurrency." MacroMania. February 3. Available at: http://andolfatto. blogspot.com/2015/02/fedcoin-on-desirabilityofgovernment.html.

Atkins, Ralph. 2018. "Swiss Voters Reject 'Sovereign Money'Initiative.” Financial Times. June 10.

Bank for International Settlements, Committee for Payments and Market Infrastructure. 2018. "Central Bank Digital Currencies.” Available at: https://www. bis.org/cpmi/publ/d174.pdf.

Bank for International Settlements. 2018. Annual Economic Report 2018. Available at: https://www.bis. org/publ/arpdf/ar2018e.pdf.

Barrdear, John, and Michael Kumhof. 2016. "The Macroeconomics of Central Bank Issued Digital Currencies." Bank of England Staff Working Paper No. 605. July.

Bech, Morten, and Rodney Garratt. 2017. "Central bank cryptocurrencies.” BIS Quarterly Review. September.

Bewley, Truman. 2005. "Fairness, Reciprocity, and Wage Rigidity." In: Herbert Gintis et al, eds. Moral Sentiments and Material Interests: The Foundations of Cooperation in Economic Life. Cambridge, MA: MIT Press.

Bordo, Michael, and Andrew Levin. 2017. “Central Bank Digital Currency and the Future of Monetary Policy." Hoover Institution Economics Working Paper 17104. Available at: https://www.hoover.org/ sites/default/files/research/docs/17104-bordo-levin_ updated.pdf.

Broadbent, Ben. 2016. "Central Banks and Digital Currencies.” Bank of England. Available at: http:// www.bankofengland.co.uk/publications/Documents/ speeches/2016/speech886.pdf.

Buiter, Willem. 2009. "Negative Nominal Interest Rates: Three Ways to Overcome the Zero Lower Bound.” NBER Working Paper No. 15118.

Central Bank of Ecuador. 2018. "Electronic Money System.” Available at: https://www.bce.fin.ec/en/ index.php/electronic-money-system.
Curry, Bill. 2019. "Growing use of $\$ 100$ bills at odds with cashless trend." Globe and Mail. January 23.

Dyson, Ben, and Graham Hodgson. 2016. "Digital Cash: Why Central Banks Should Start Issuing Electronic Money." Positive Money. January. Available at: http:// positivemoney.org/wp-content/uploads/ 2016/01/ Digital_Cash_WebPrintReady_20160113.pdf.

Fisher, Irving. 1913. “A Compensated Dollar.” Quarterly Journal of Economics. 27:213-235, 385-397. February.

Friedman, Milton. 1960. A Program for Monetary Stability. New York: Fordham Press.

Fung, Ben, and Hanna Halaburda. 2016. "Central Bank Digital Currencies: A Framework for Assessing Why and How." Bank of Canada Staff Discussion Paper. Available at: http://www.bankofcanada. ca/2016/11/staffdiscussion-paper-2016-22/.

Hayek, Friedrich. 1978. Denationalization of Money - The Argument Refined: An Analysis of the Theory and Practice of Concurrent Currencies ( $2^{\text {nd }}$ edition). London: Institute of Economic Affairs.

Henry, Christopher, Kim Huynh, and Angela Welte. 2018. "2017 Methods-of-Payment Survey Report." Bank of Canada Staff Discussion Papers 2018-17. Available at: https://www.bankofcanada.ca/wpcontent/uploads/2018/12/sdp2018-17.pdf.

Jevons, William Stanley. 1875. "A Tabular Standard of Value." In: Money and the Mechanism of Exchange. Chapter 25. Available at: http://econlib.org/ YPDBooks/Jevons/jvnMME25.html.

Ketterer, Juan Antonio, and Gabriela Andrade. 2016. "Digital Central Bank Money and the Unbundling of the Bank Function.” Inter-American Development Bank Discussion Paper 449.

Lane, Timothy. 2018. “Decrypting' Crypto.” Speech given at the Haskayne School of Business, University of Calgary by Bank of Canada Deputy Governor. October 1. Available at: https://www. bankofcanada.ca/wp-content/uploads/2018/10/ remarks-011018.pdf. 
Marshall, Alfred. 1887. "Remedies for Fluctuations of General Prices.” The Contemporary Review. 51:355375. March.

McAndrews, Jamie. 2017. “The Case for Cash.” Asian Development Bank Institute Working Paper. No 679.

Mersch, Yves. 2017. "Digital Base Money: An Assessment from the ECB's Perspective." Available at: https://www.ecb.europa.eu/press/key/date/2017/ html/sp170116.en.html.

Nicolaisen, Jon. 2017. "What Should the Future Form of Our Money Be?" Speech by the Norges Bank Deputy Governor. April 25. Available at: http://www.norges-bank.no/en/published/ speeches/2017/2017-04-25-dnva/.

Rogoff, Kenneth. 2016. The Curse of Cash. Princeton, NJ: Princeton University Press.
Simons, Henry. 1936. "Rules vs. Authorities in Monetary Policy." Journal of Political Economy. 44:130. February.

Skingsley, Cecilia. 2016. "Should the Riksbank Issue e-Krona?" Speech by Sveriges Riksbank Deputy Governor. November 16. Available at: http://archive. riksbank.se/Documents/Tal/Skingsley/2016/tal_ skingsley_161116_eng.pdf.

Tobin, James. 1987. “The Case for Preserving Regulatory Distinctions." Proceedings, Federal Reserve Bank of Kansas City. pp. 167-183.

White, Larry. 2018. “The World's First Central Bank Electronic Money Has Come - And Gone: Ecuador, 2014-2018." Cato Institute. Washington, DC.

Wicksell, Knut. 1898. Interest and Prices: A Study of the Causes Regulating the Value of Money. Jena, Sweden: Gustav Fischer Press. 


\section{NOTES:}




\section{ReCent C.D. Howe institute Publications}

April 2019 Chaykowski, Richard P. “Time to Tweak or Re-boot? Assessing the Interest Arbitration Process in Canadian Industrial Relations.” C.D. Howe Institute Commentary 539.

March 2019 Baldwin, Bob. “The Evolving Wealth of Canadians Approaching Retirement.” C.D. Howe Institute Working Paper.

March 2019 Grace, Chuck. "Next Gen Financial Advice: Digital Innovation and Canada's Policymakers.” C.D. Howe Institute Commentary 538.

March 2019 McKenzie, Kenneth, and Michael Smart. "Tax Policy Next to the Elephant: Business Tax Reform in the Wake of the US Tax Cuts and Jobs Act." C.D. Howe Institute Commentary 537.

March 2019 Jordaan, Sarah Marie, and Kate Konschnik. "Measuring and Managing the Unknown: Methane Emissions from the Oil and Gas Value Chain.” C.D. Howe Institute E-Brief.

February 2019 Lortie, Pierre. "Entrepreneurial Finance and Economic Growth: A Canadian Overview.” C.D. Howe Institute Commentary 536.

February 2019 Blomqvist, Åke, and Rosalie Wyonch. "High Drug Prices, Big R\&D Spenders and "Free Riders": Canada in the Topsy Turvy World of Pharmaceuticals.” C.D. Howe Institute Commentary 535.

February 2019 Sprague, Grant, and Grant Bishop. “A Crisis of Our Own Making: Prospects for Major Natural Resource Projects in Canada.” C.D. Howe Institute Commentary 534.

February 2019 Naugler, Christopher, and Rosalie Wyonch. "What the Doctor Ordered: Improving the Use and Value of Laboratory Testing." C.D. Howe Institute Commentary 533.

février 2019 Wyonch, Rosalie, et Abby Sullivan. "Santé et bonne scolarité : Les programmes d'alimentation saine au Canada” Institut C.D. Howe commentaire $\mathrm{N}^{\circ} 532$.

February 2019 Wyonch, Rosalie, and Abby Sullivan. "Health and Grades: Nutrition Programs for Kids in Canada." C.D. Howe Institute Commentary 532.

February 2019 Robson, William B.P., and Alexandre Laurin. "Less Debt, More Growth: A Shadow Federal Budget for 2019.” C.D. Howe Institute Commentary 531.

\section{SUPPORT THE INSTITUTE}

For more information on supporting the C.D. Howe Institute's vital policy work, through charitable giving or membership, please go to www.cdhowe.org or call 416-865-1904. Learn more about the Institute's activities and how to make a donation at the same time. You will receive a tax receipt for your gift.

\section{A REPUTATION FOR INDEPENDENT, NONPARTISAN RESEARCH}

The C.D. Howe Institute's reputation for independent, reasoned and relevant public policy research of the highest quality is its chief asset, and underpins the credibility and effectiveness of its work. Independence and nonpartisanship are core Institute values that inform its approach to research, guide the actions of its professional staff and limit the types of financial contributions that the Institute will accept.

For our full Independence and Nonpartisanship Policy go to www.cdhowe.org. 

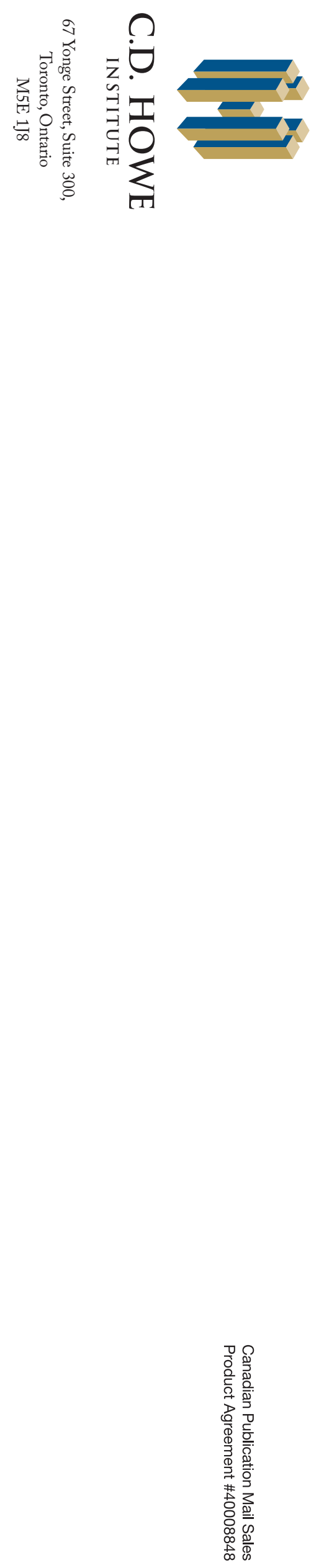